\title{
GESTÃO INCLUSIVA DA PESSOA COM DEFICIÊNCIA NO AMBIENTE DE TRABALHO
}

\section{INCLUSIVE MANAGEMENT OF PERSONS WITH DISABILITIES IN THE WORKPLACE}

\author{
Evandro Ferigato ${ }^{1}$
}

\begin{abstract}
RESUMO
Este artigo aborda uma questão de diversidade no contexto laboral a partir de uma revisão da literatura sobre o tema e um estudo empírico sobre o respeito pela inclusão de profissionais com algum tipo de deficiência no mercado de trabalho brasileiro. Nessa pesquisa, procurou-se conhecer as dificuldades enfrentadas no processo pelos profissionais com deficiências em encontrar uma vaga de trabalho e também pelos empregadores. Os fatores relacionados ao aumento do emprego de pessoas com deficiência intelectual incluem opiniões do empregador, conteúdo do trabalho, cultura no local de trabalho e apoio de treinadores e as dificuldades no processo de inclusão, como a Lei 8.231 / 91 (Lei de Cotas) e as organizações têm uma responsabilidade moral de não desmotivar pessoas no local de trabalho, mas sim garantir que tenham participação total no trabalho (Schur et al. 2009). É importante que os empregadores aprendam mais maneiras pelas quais os funcionários podem ser integrados ao local de trabalho (Tomlin e Haring 2010). Brendle, Lock e Smith (2019) argumentam que os empregadores precisam de treinamento em indicadores de emprego, como supervisão, treinamento no local de trabalho e reforço positivo antes da entrada de funcionários em potencial no local de trabalho. Um indicador chave é a comunicação pela qual um empregador e um funcionário em potencial desenvolvem entendimentos sobre tarefas específicas do trabalho e quaisquer objetivos relacionados à realização dessas tarefas e fazendo parte ao setor de Recursos Humanos se utilizarem de técnicas práticas para enfrentar os desafios no que se diz a que essa lei impõe às organizações.
\end{abstract}

PALAVRAS-CHAVE: Inclusão de profissionais com deficiência. Lei 8.231 / 91. Recursos Humanos. Desafios para os líderes.

\begin{abstract}
This article addresses an issue of diversity in the work context from a literature review on the topic and an empirical study on the respect for the inclusion of professionals with some type of disability in the Brazilian labor market. In this research, we sought to know the difficulties faced in the process by professionals with disabilities in finding a job vacancy and also by employers. Factors related to the increase in the employment of people with intellectual disabilities include opinions of the employer, content of work, culture in the workplace and support from coaches and difficulties in the inclusion process, such as Law 8.231 / 91 (Quota Law) and organizations have a moral responsibility not to demotivate people in the workplace, but to ensure that they have full participation in the work (Schur et al. 2009). It is important that employers learn more ways in which employees can be integrated into the workplace (Tomlin and Haring 2010). Brendle, Lock and Smith (2019) argue that employers need training on employment indicators, such as supervision, training in the workplace and positive reinforcement before potential employees enter the workplace. A key indicator is the communication by which an employer and a potential employee develop understandings about specific work tasks and any objectives related to the accomplishment of those tasks and being part of the Human Resources sector using practical techniques to face the challenges in says what this law imposes on organizations.
\end{abstract}

KEYWORDS: Inclusion of professionals with disabilities. Law 8,231 / 91. Human Resources. Challenges for leaders.

\footnotetext{
${ }^{1}$ Mestre em Administração Micro e Pequenas Empresas (UNIFACCAMP) Centro Universitário Campo Limpo Paulista (2015 / 2018); Pós-graduado em Gestão de Pessoas (UNIFACCAMP) Centro Universitário Campo limpo Paulista (2014); Pósgraduado em Logística pela (UNIFACCAMP) Centro Universitário Campo Limpo Paulista (2013); Graduado em Logística (UNIFACCAMP) Centro Universitário Campo Limpo Paulista (2012); Graduado em Publicidade e Propaganda Faculdade Luiz Rosa (2000); Professor Mestre Universitário MBA Pós Graduação e Graduação UNIFACCAMP (Centro Universitário Campo Limpo Paulista) e FFRAMO (Faculdade Francisco Morato) 2013 E-mail: evandroferigato@gmail.com - ORCID: https://orcid.org/0000-0003-2044-1324
} 


\title{
RECIMA21 - REVISTA CIENTÍFICA MULTIDISCIPLINAR
}

\author{
GESTÃO INCLUSIVA DA PESSOA COM DEFICIÊNCIA NO \\ AMBIENTE DE TRABALHO \\ Evandro Ferigato
}

\section{INTRODUÇÃO}

A preocupação com a construção de uma sociedade inclusiva aumentou em todo o mundo. A questão requer discussões e medidas práticas no contexto do emprego, uma vez que o trabalho é um fator significativo na construção da identidade de um indivíduo, pois fornece equilíbrio psíquico, inclusão social, oportunidades de aprendizado contínuo e pode impactar positivamente a vida de uma pessoa.

A inclusão social no local de trabalho deve fornecer aos trabalhadores as condições necessárias para que se sintam respeitados em suas condições - independentemente de suas limitações - e permitir que percebam sua capacidade de contribuir para a sociedade. Para oferecer tais condições, a sociedade é constantemente convidada a promover mudanças destinadas a acolher todos os indivíduos sem discriminação, independentemente de emprego, lazer ou outras situações da vida cotidiana.

Nas discussões sobre inclusão social, dentro da Gestão de Recursos Humanos - uma área que faz interface com Administração de Empresas, Engenharia de Produção, Psicologia Organizacional e outras áreas do conhecimento pouco se debateu sobre ações mais práticas para tornar mais eficaz à inclusão de profissionais com deficiência. A dedução nos diz que há uma brecha, principalmente na literatura nas áreas de Administração de Empresas e Engenharia de Produção. Portanto, este artigo pretende ajudar a preencher as lacunas encontradas nesta discussão.
Abordar a diversidade no contexto do trabalho é um grande desafio. Tal dificuldade é expressa em ações discriminatórias das organizações, representadas por gerentes que demonstram resistência à contratação de profissionais com deficiência. Há evidências explícitas dessa resistência quando leis estabelecidas obrigam organizações públicas e privadas a poupar uma cota de vagas para esses profissionais.

Percebe-se que a legislação para esse tipo de contratação em empresas privadas não é tão recente, mas as dificuldades enfrentadas pelos gestores - principalmente no departamento de Recursos Humanos - ainda são pesadas e exigem que esse debate esteja sempre na agenda de trabalhos de pesquisa, para que um diálogo multidisciplinar possa estar atento à proposição de soluções atuais para esse tópico.

O objetivo deste artigo é apresentar algumas das dificuldades enfrentadas nesse processo por profissionais com deficiência, em busca de emprego, e por empregadores, através de levantamentos dos dados de artigos, publicações e sites específicos no tema.

Os resultados mostram que tanto os profissionais com deficiência quanto as organizações enfrentam dificuldades nesse processo de inclusão, resultando em uma observação parcial da Lei 8.331 / 91 (Lei de Quotas).

\section{REFERENCIAL TEÓRICO}

Serão discutidos no referencial teórico os temas abaixo, objetivando em alicerçar a pesquisa: 


\section{RECIMA21 - REVISTA CIENTÍFICA MULTIDISCIPLINAR}

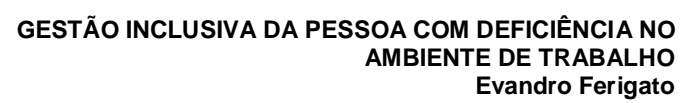

- Contextualizando a deficiência no Brasil

- A legislação brasileira para pessoas com deficiência e o acesso ao local de trabalho

- A inclusão de profissionais com deficiência: algumas discussões

- Desafios para o setor de Recursos Humanos no gerenciamento de diversidades.

- A experiência de pessoas com deficiência

- Três fatores que contribuem para a experiência de exclusão social.

- Desafios para os líderes.

- Quais podem ser os atributos de liderança

\subsection{Contextualizando a deficiência no Brasil}

A literatura sobre o assunto revela, ao longo dos anos, alguma dificuldade na adoção de designação adequada para pessoas com deficiência. Para Sassaki (2003), os tempos trazem o uso de termos cujos significados são compatíveis com os valores em vigor na sociedade, à medida que evolui em seu relacionamento com pessoas com deficiência.

Sassaki (2003) pesquisa muitos termos e significados dos anos 1960 a 2005, variando entre: inválido, incapaz, deficiente, aleijado, deficiente, excepcional, pessoas especiais, pessoas que têm direitos especiais, para o termo que está sendo usado atualmente por outros autores "pessoa com deficiência". O autor ressalta que os movimentos mundiais de pessoas com deficiência discutiram o nome pelo qual essas pessoas desejam ser chamadas. Em todo o mundo, eles definiram que querem ser chamados de "pessoas com deficiência" em todos os idiomas.
A definição de pessoas com deficiência, de acordo com os artigos 2 e 3 do Estatuto Brasileiro da Pessoa com Deficiência (Brasil, 2013):

- Artigo 2. Pessoas com deficiência incluem aquelas que sofrem de deficiências físicas, mentais, intelectuais ou sensoriais em longo prazo que, em interação com várias barreiras, podem dificultar sua participação plena e efetiva na sociedade, em igualdade de condições com as demais.

- Artigo 3. Para o reconhecimento dos direitos estabelecidos nesta Lei, serão consideradas deficiências aquelas que causem prejuízo às funções ou estrutura do corpo relacionado às habilidades comunicativas, mentais, intelectuais, sensoriais ou motoras (Brasil, 2013, p. 2).

Dados do Censo 2010 do IBGE (Instituto Brasileiro de Geografia e Estatística) mostram que quase 46 milhões de brasileiros - cerca de $24 \%$ da população - relataram ter pelo menos uma das deficiências investigadas (mental, motora, visual e auditiva). Esses dados mostram que existe uma parcela significativa da população com algum tipo de deficiência e merece atenção quanto à necessidade de rever, pela sociedade, os direitos dessas pessoas de entrar no mercado de trabalho e usufruir de todos os serviços: saúde, cursos de qualificação e treinamento profissional, além de atividades recreativas e outras.

O maior percentual foi encontrado na região Nordeste $(26,6 \%)$, enquanto as regiões Sul e Centro-Oeste apresentaram as menores proporções (22,5\%). Rio Grande do Norte $(27,8 \%)$, Paraíba $(27,8 \%)$ e Ceará $(27,7 \%)$ 


\title{
RECIMA21 - REVISTA CIENTÍFICA MULTIDISCIPLINAR
}

\author{
GESTÃO INCLUSIVA DA PESSOA COM DEFICIÊNCIA NO \\ AMBIENTE DE TRABALHO \\ Evandro Ferigato
}

apresentaram os maiores percentuais. Roraima $(21,2 \%)$, Santa Catarina $(21,3 \%)$ e Mato Grosso do Sul $(21,5 \%)$ tiveram a menor incidência (IBGE, 2010).

O comprometimento visual foi o mais comum, atingindo 35,8 milhões de pessoas com dificuldade de enxergar (18,8\%), mesmo usando óculos ou lentes de contato. A deficiência visual grave (pessoas que relataram ter grande dificuldade em ver ou não conseguiam ver) atingiu 6,6 milhões de pessoas, 506,3 mil das quais eram cegas $(0,3 \%)$. O comprometimento da locomoção foi encontrado em 13,3 milhões de pessoas $(7,0 \%)$. O comprometimento motor

grave foi declarado por 4,4 milhões de pessoas, das quais 734,4 mil não conseguiam andar ou subir escadas $(0,4 \%)$. A deficiência auditiva afetou 9,7 milhões de pessoas (5,1\%), e a deficiência auditiva grave foi declarada por 2,1 milhões de pessoas, das quais 344,2 mil eram surdas $(0,2 \%)$. A deficiência mental ou intelectual também considerada grave foi declarada por 2,6 milhões de pessoas, representando $1,4 \%$ da população (IBGE, 2010).

Dados do Censo do IBGE (IBGE, 2010) também revelaram que persistem desigualdades em relação às pessoas com deficiência, com menores taxas de matrícula em comparação à população que não possui nenhuma das deficiências investigadas.

Em 2010, a população com deficiência empregada representava $23,6 \%$ (20,4 milhões) do número total de pessoas empregadas $(86,4$ milhões). Dos 44 milhões de pessoas com deficiência em idade ativa (10 anos ou mais),
53,8\% (23,7 milhões) não estavam empregados. Em relação à população total não ocupada $(75,6$ milhões), a população com deficiência representou 31,3\% (IBGE, 2010).

Em relação à taxa de atividade por tipo de deficiência, a deficiência mental foi a que mais limitou a inserção no mercado de trabalho, tanto para homens quanto para mulheres (cujas taxas de atividade foram $22,2 \%$ e $16,1 \%$, respectivamente). A deficiência visual foi a que menos influenciou a taxa de atividade, que foi de $63,7 \%$ para homens e $43,9 \%$ para mulheres. $O$ mesmo foi observado para o nível de atividade que, em geral, foi de $17,4 \%$ para pessoas com deficiência mental e $48,4 \%$ para pessoas com deficiência visual. 40,2\% das pessoas com deficiência empregadas possuem contrato formal (IBGE, 2010).

\subsection{A legislação brasileira para pessoas com deficiência e o acesso ao local de trabalho}

A Convenção 159 sobre Reabilitação Profissional e Emprego de Pessoas com Deficiência da Organização Internacional do Trabalho foi adotada em 1983 e considera que todas as pessoas com possibilidades reduzidas são desabilitadas para o trabalho - devido a uma deficiência física ou mental devidamente comprovada - para garantir e manter um emprego adequado e avançar nele.

A partir desse padrão internacional, 0 Brasil, buscando facilitar a inclusão de profissionais com deficiência ou reabilitados para o trabalho, instituiu a Lei n. 8.112/90 e Lei n. 8.213 / 91 (também chamado de Lei de cotas). A primeira lei define a economia de até $20 \%$ das 


\section{RECIMA21 - REVISTA CIENTÍFICA MULTIDISCIPLINAR}

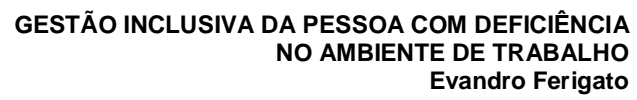

vagas nas seleções de serviço público na União para profissionais com deficiência. Seguindo a mesma orientação, a Lei oㅜ 8.213 / 91, no artigo 93, estabelece que empresas privadas com 100 funcionários ou mais devem contratar pessoas qualificadas ou reabilitadas com deficiência. A cota especificada varia de $2 \%$ a $5 \%$ do número de empregados contratados formalmente pela empresa, em relação direta ao tamanho de sua equipe. O não cumprimento deste preceito legal é considerado uma prática discriminatória proibida pela Constituição Federal de 1988.

A existência dessas leis brasileiras para a inclusão de profissionais com deficiência revela um grande interesse em investir na inclusão social através do trabalho, no entanto, fazer com que as empresas observem essas leis tem sido um desafio tanto para os profissionais envolvidos quanto para o poder público, que geralmente só desempenha inspeções ocasionais, especialmente em cidades menores.

A literatura revela estudos com análises detalhadas com o objetivo de entender como a inclusão desses profissionais vem ocorrendo. Um desses estudos foi desenvolvido por Ribeiro \& Carneiro (2009) que estudaram a adesão à Lei no 8.213 / 91 em empresas do Estado de Minas Gerais. A pesquisa envolveu o processo de emissão de avisos, devido ao descumprimento das leis, conforme realizado pelo órgão competente no período 2000-2007. Os resultados mostraram baixa adesão em relação à referida lei e as principais estratégias defensivas adotadas pelas empresas para contornar, adiar ou minimizar a contratação obrigatória de profissionais com deficiência.
No total, apenas 1.572 das 4.982 vagas para pessoas com deficiência determinadas por lei foram preenchidas, representando $31,6 \%$ do total. Existem muitas estratégias que as empresas usam para adiar a contratação de profissionais com deficiência. Uma delas é reduzir os funcionários contratados diretamente, substituindo-os por terceirizados. Dessa forma, o índice de cálculo da cota a ser atendida é reduzido (Ribeiro \& Carneiro, 2009). Essas estratégias merecem discussão porque 0 objetivo é incentivar a inclusão de profissionais, e os empregadores desempenham um papel fundamental na proposição de ações para garantir a inclusão desses trabalhadores.

De maneira geral, a pesquisa revelou que a reação das empresas quando notificadas busca, basicamente, justificar o descumprimento da Lei no 8.213 / 91 . Suas reivindicações estão relacionadas às peculiaridades dos ramos de atividade. Alguns afirmam que suas atividades são caracterizadas por altos graus de risco e perigo. Assim, defendem a exclusão das posições que consideram inadequadas para pessoas com deficiência do cálculo da cota, restringindo-as a atividades de natureza administrativa ou de manutenção de papel. Essa situação foi percebida em empresas dos setores industrial, construção civil e saúde. Existem empresas que elevam os padrões de qualificação profissional e de experiência para preencher as vagas oferecidas e restringem as possibilidades de possíveis candidatos com as habilidades necessárias para preencher essas vagas. Há também tentativas de classificar, como pessoas com deficiência, funcionários que já pertencem aos funcionários da empresa. Uma 


\section{RECIMA21 - REVISTA CIENTÍFICA MULTIDISCIPLINAR}

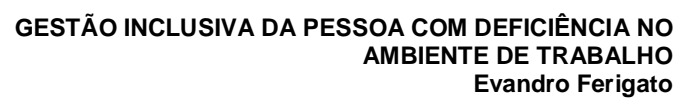

empresa industrial do setor automotivo classificou 471 funcionários como pessoas com deficiência, para uma cota de emprego de 519 pessoas; quase todos apresentavam deficiência auditiva leve. Há também tentativas de contestar a aplicação da lei à empresa, negligenciando sua relevância. É o caso de entidades dedicadas à assistência social e religiosa, para as quais o fato de desenvolver ações filantrópicas seria suficiente para isentálas do cumprimento da cota (Ribeiro \& Carneiro, 2009). Os autores criticam a Lei o 8.213 / 91, considerando-a parcial e exclusiva, pois a seletividade na contratação tende a discriminar pessoas com deficiências mais graves, como deficientes visuais, auditivos, portadores de transtornos e sofrimentos mentais e pessoas em cadeira de rodas.

\subsection{A inclusão de profissionais com deficiência: algumas discussões}

A inclusão social de pessoas com deficiência é uma questão que tem sido discutida na literatura sob diferentes perspectivas, como:

- Artigo 34. Uma pessoa com deficiência tem o direito de trabalhar de forma livre e aceitável em um ambiente acessível e inclusivo, em igualdade de condições com outras pessoas.

$\S 1^{\circ}$ As entidades jurídicas públicas, privadas ou de qualquer natureza são obrigadas a garantir ambientes de trabalho acessíveis e inclusivos.

$\S$ 2ำ A pessoa com deficiência tem direito, em pé de igualdade com as demais pessoas, a condições justas e favoráveis de

trabalho, incluindo remuneração igual por trabalho de igual valor (Brasil, 2015, p. 1).

No Brasil, há muito interesse em discutir a diversidade, enfatizando a inserção de profissionais com deficiência no local de trabalho. Alguns estudos objetivaram identificar as facilidades e dificuldades das pessoas a serem inseridas e permanecer no mercado de trabalho (Hoffmann et al., 2013 ; Simonelli \& Camarotto, 2011 ; Violante \& Leite, 2011 ; Oliveira et al., 2009 ; Ribeiro \& Carneiro, 2009 ; Moraes de Souza, 2009 ; Rodrigues et al., 2009 ; Carvalho-Freitas, 2009 ; Carvalho-Freitas \& Marques, 2007).

Considerando que a literatura demonstrou preocupação com o tema, pode-se deduzir que é relevante no contexto trabalhista contemporâneo, justificando assim a discussão abordada neste artigo. Nosso objetivo é contribuir para ampliar o debate, principalmente nas áreas de Engenharia de Produção e Administração de Empresas, onde ainda existem lacunas na abordagem do assunto. Essas são áreas de conhecimento muito importantes que se relacionam com os estudos sobre Gestão de Pessoas.

Uma pesquisa de Hoffmann et al. (2013), buscou identificar o perfil profissional das pessoas com deficiência no contexto do serviço público federal, mapeando as características vinculadas às suas relações de trabalho. Os resultados revelaram que há igualdade de gênero na inclusão de pessoas com deficiência, há maturidade na carreira, progressão na qualificação sem, no entanto, envolver treinamento específico para seus tipos de necessidades. Tais dados revelam uma lacuna 


\title{
RECIMA21 - REVISTA CIENTÍFICA MULTIDISCIPLINAR
}

\author{
GESTÃO INCLUSIVA DA PESSOA COM DEFICIÊNCIA NO \\ AMBIENTE DE TRABALHO \\ Evandro Ferigato
}

em relação às ações em Gestão de Recursos Humanos, uma vez que uma das atividades essenciais para o desenvolvimento profissional é o treinamento.

Simonelli \& Camarotto

apresentaram uma abordagem mais prática da deficiência, partindo da análise de situações reais do local de trabalho em que existe a possibilidade de inserção de profissionais com deficiência, onde esses trabalhadores possam desenvolver seu potencial.

A empregabilidade de pessoas com deficiência em empresas de médio e grande porte em uma cidade a oeste de São Paulo tem sido objeto de pesquisa de Violante \& Leite (2011), cujos resultados mostraram que apenas um terço das empresas privadas cumpre a lei. As políticas de negócios no contexto estudado

priorizam a contratação de pessoas cujas deficiências não exigem modificações estruturais ou que representam um aspecto favorável à produção. A maioria dos entrevistados mostrou alguma contradição entre fala e prática; eles falaram sobre direitos iguais para todas as pessoas; no entanto, grande parte delas ainda não realiza ações de apoio para atender à demanda desses profissionais e espera que os próprios trabalhadores se ajustem à situação apresentada.

O mapeamento das instituições de assistência e reabilitação, suas ações e o público atendido na cidade de São Carlos / São Paulo foi objeto de interesse em uma pesquisa de Rodrigues et al. (2009). Os autores concluíram que existe uma baixa taxa de empregabilidade entre pessoas com deficiência, e as instituições pesquisadas apontam como limitações à inclusão os baixos níveis de escolaridade dessas pessoas, a inadequação do sistema de transporte público para pessoas com deficiência física, a falta de recursos e estrutura para qualificá-los. Dados oficiais da Gerência Regional de Trabalho e Emprego em São Carlos mostram que $51,3 \%$ das cotas não foram cumpridas. Esses dados comprovam que, embora haja um esforço das instituições pesquisadas pelos autores, é necessário dialogar com outras instituições - como o poder público municipais, além de outras que possam oferecer cursos de treinamento e qualificação para aumentar o acesso de profissionais com deficiência, na cidade.

Oliveira et al. (2009) analisaram as políticas de emprego adotadas nos Estados Unidos, União Europeia e Brasil para promover a inclusão de pessoas com deficiência no mercado de trabalho. Concluíram que há avanços e divergências nas políticas trabalhistas e que elas estão relacionadas às particularidades de cada contexto; no entanto, existe uma preocupação comum em garantir às pessoas com deficiência o acesso a uma atividade profissional.

Ribeiro e Carneiro (2009) abordam as leis brasileiras relacionadas à inclusão de pessoas com deficiência no local de trabalho. Para isso, os autores pesquisaram a adesão à Lei 8.213 / 91 no que diz respeito à sua implementação e as dificuldades que as empresas em Minas Gerais têm enfrentado.

A trajetória pessoal e profissional dos profissionais com deficiência que trabalham em uma Organização Pública Federal foi tema de 


\section{RECIMA21 - REVISTA CIENTÍFICA MULTIDISCIPLINAR}

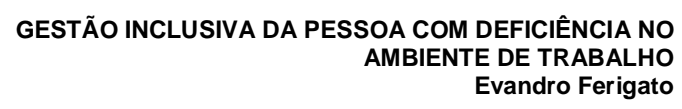

interesse de Moraes de Souza (2009), que demonstrou, a partir dos relatos dos entrevistados, que o apoio de familiares e amigos, além de uma qualificação profissional, são fatores muito importantes para superar as dificuldades de inserção no local de trabalho. Tais dados revelam que o indivíduo sozinho não pode superar as barreiras sociais e estruturais e precisa procurar ajuda nesse contexto.

Ao adotar o método de análise histórica dos principais padrões de comportamento que permanecem em visões compartilhadas ao longo do tempo, Carvalho-Freitas \& Marques (2007) identificaram seis matrizes de interpretação sobre deficiência. Tais matrizes podem ser instrumentos para entender a diversidade nas organizações: a matriz de meios de subsistência / sobrevivência; a matriz da sociedade ideal e a função instrumental da pessoa; a matriz espiritual; a matriz da normalidade; a matriz de inclusão social e a matriz técnica. Essas matrizes ajudam a entender como as empresas interpretam e agem em relação à inclusão. Os autores concluem que a coexistência de aspectos das diferentes matrizes indica que o gerenciamento da diversidade pode constituir uma tarefa complexa, pois implica gerenciar conceitos de deficiência, às vezes antagônicos na mesma empresa. Essa questão pode afetar negativamente não apenas o processo de inclusão, mas também 0 trabalho desses trabalhadores.

A avaliação do contexto atual de trabalho e local de trabalho em relação à matriz que discute 0 modelo de subsistência / sobrevivência (Carvalho-Freitas \& Marques,
2007) é apropriada; a deficiência era considerada um fator de dificuldade na sobrevivência / sustento das pessoas, uma vez que um corpo deformado ou um corpo em falta das funções que assegurariam vigor e força dificilmente poderiam ajudar na agricultura ou na guerra. Nessa perspectiva, a inserção da pessoa com deficiência seria aceita apenas mediante comprovação das possíveis contribuições sociais.

Uma interpretação dessa matriz pode ser observada de forma implícita e modificada nos tempos atuais, como se vê nos fatos que vêm ocorrendo, por exemplo, nas dificuldades que muitas organizações brasileiras alegam em cumprir a Lei 8213/91 (as cotas AJA - Ação Jovem Acessível). Eles afirmam que não conseguem encontrar profissionais com habilidades técnicas suficientes que possam contribuir para seus processos de produção.

Assim, é necessário um esforço extra desses profissionais para provar suas capacidades e habilidades. Algumas empresas também não se consideram corresponsáveis pela inclusão desses trabalhadores em atividades de qualificação profissional.

No caso de políticas sociais voltadas para as necessidades das pessoas com deficiência, Sassaki (2003) caracteriza dois modelos de interpretação da deficiência, e o primeiro é o modelo de integração social que aborda o ponto de vista médico da deficiência e deu origem às práticas sociais. O objetivo dessas práticas era ajustar a pessoa com deficiência para viver em sociedade. $\mathrm{O}$ outro modelo é a inclusão social, em que a sociedade se adapta às necessidades das pessoas com 


\section{RECIMA21 - REVISTA CIENTÍFICA MULTIDISCIPLINAR}

deficiência e essas pessoas buscam seu desenvolvimento na sociedade. Entendemos que as políticas públicas adotadas por muitos países, como a Lei 8.213 / 91 no Brasil, colidem com o modelo discutido pelo autor, pois essa lei sugere que as empresas, sempre que possível, façam adaptações estruturais para a inclusão dos profissionais com deficiência e / ou profissionais reabilitados.

\subsection{Desafios para o setor de Recursos Humanos no gerenciamento de diversidades}

A Gestão de Pessoas é uma área de interesse de Engenharia de Produção, Administração de Empresas e Psicologia Organizacional; para isso, é necessário discutir a inclusão social por meio do trabalho de pessoas com deficiência na esfera dessas áreas do conhecimento. O diálogo interdisciplinar que a Gestão de Recursos Humanos exige e promove podendo enriquecer a proposta de ações concretas e sustentáveis em relação à inclusão de profissionais com deficiência e profissionais reabilitados no mercado formal de trabalho.

Sobre a legislação, 0 artigo 7 da Convenção sobre reabilitação profissional e emprego (pessoas com deficiência), de 1983, traz a seguinte recomendação:

- As autoridades competentes devem tomar medidas com vista a fornecer e avaliar orientação profissional, formação profissional, colocação, emprego e outros serviços conexos que permitam às pessoas com deficiência garantir, manter e avançar no emprego; os serviços existentes para trabalhadores geralmente devem, sempre que possível e apropriado, ser utilizados com as adaptações necessárias (Brasil, 1983).

Os campos de conhecimento envolvidos nesta discussão devem dialogar com esta legislação e com o poder público para alinhar ações e práticas efetivas quando executadas pela gerência de Recursos Humanos.

Um dos principais desafios enfrentados pelo setor responsável pela gestão de Recursos Humanos nesse contexto é desenvolver, implantar e gerenciar um amplo programa de empregabilidade para garantir direitos a oportunidades para todos, cujo foco é o potencial dos profissionais e não o tipo de deficiência que eles enfrentam ter.

A sociedade brasileira está se esforçando para construir um contexto que reconheça, respeite e acolha com dignidade a diversidade que a compõe (Schwartz \& Haber, 2006). Devemos considerar que a Lei 8.213 / 91 já é um grande passo adiante. O processo é complexo e demorado, pois implica mudanças na maneira como a sociedade e os empregadores pensam e se comportam, e na inserção de adaptações objetivas que atendem às necessidades específicas e peculiares desses trabalhadores. Assim, a empresa que contrata funcionários com deficiência deve ter um programa estruturado para ajustar sua estrutura física, recrutamento, seleção, contratação e desenvolvimento e não apenas contratar formalmente para cumprir a lei. Do ponto de vista da engenharia de produção, por exemplo, esse processo pode ser considerado oneroso, porque as mudanças estruturais geralmente exigem despesas significativas. 


\section{RECIMA21 - REVISTA CIENTÍFICA MULTIDISCIPLINAR}

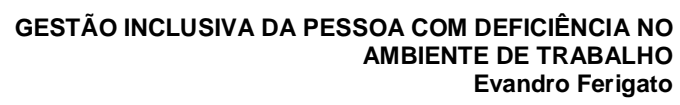

Em relação às ações em Gestão de Pessoas, Ávila-Vitor \& Carvalho-Freitas (2012) visou aprender o ponto de vista das pessoas com deficiência já incluída no local de trabalho, no que diz respeito à relação entre suas percepções dos valores organizacionais e como elas veriam a deficiência no local de trabalho. Os resultados revelaram que existe uma correlação negativa entre a percepção de prestígio e a maneira como a empresa vê a normalidade. Pessoas com deficiência relacionam o prestígio da empresa a uma concepção de deficiência que não as coloca como desviantes de um ser humano comum. A pesquisa também identificou outros dados considerados importantes nesse processo de inclusão, dentre os quais o reconhecimento da inclusão como valor organizacional, a necessidade de adaptação das condições de trabalho.

No contexto das ações dos gestores de Recursos Humanos, Carvalho-Freitas (2009) procurou analisar as possíveis relações entre a maneira como esses gerentes percebem a deficiência, a adequação das condições de trabalho e a satisfação das pessoas com deficiência em relação a aspectos relevantes para manter a qualidade de vida no trabalho, em uma grande empresa brasileira com mais de mil funcionários com deficiência. Os resultados revelaram a existência de relações significativas entre as concepções de deficiência compartilhadas pelos gestores e a adequação das condições e práticas de trabalho na empresa. Também foram encontradas implicações dos conceitos de deficiência e da adequação das condições e práticas de trabalho para a satisfação das pessoas com deficiência. As possibilidades de carreira para essas pessoas são uma das práticas de gestão de recursos humanos que podem ser destacadas.

Quanto à concepção baseada em premissas de inclusão, $81 \%$ dos gerentes expressam a opinião de que é necessário mudar o ambiente de trabalho para que seja acessível a todos, o que é uma tendência atual. Em relação à percepção de desempenho, 92\% dos gerentes avaliaram positivamente 0 desempenho das pessoas com deficiência. De maneira geral, os entrevistados afirmaram que as pessoas com deficiência têm desempenho semelhante ao das outras pessoas e que a inserção dessas pessoas não tem impacto negativo na competitividade da empresa (Carvalho-Freitas, 2009, p. 131).

A implantação de um programa abrangente parece complexa; no entanto, garante que os esforços realizados na contratação não sejam desperdiçados e aumenta as taxas de retenção. Se a pessoa com deficiência tiver atribuições claras e definidas e receber treinamento adequado para desenvolvêlas, elas terão responsabilidades e serão produtivas como os outros funcionários. É uma situação ganha-ganha para funcionários e empregadores (Schwartz \& Haber, 2006).

\section{A proposta de Simonelli \& Camarotto} (2011) pode contribuir nessa perspectiva. Os autores utilizaram um conjunto de métodos e técnicas baseados no conhecimento em Análise Ergonômica da Atividade e Terapia Ocupacional para a construção de um modelo 


\title{
RECIMA21 - REVISTA CIENTÍFICA MULTIDISCIPLINAR
}

\author{
GESTÃO INCLUSIVA DA PESSOA COM DEFICIÊNCIA NO \\ AMBIENTE DE TRABALHO \\ Evandro Ferigato
}

para indicar as habilidades necessárias para a realização das atividades do trabalho industrial.

Foi possível identificar trabalhos que poderiam ser potencialmente ocupados por pessoas com deficiência, como incentivo às ações das empresas na política de contratação dessa população.

Uma observação importante feita por Carvalho-Freitas (2009) refere-se à necessidade de treinamento, não apenas para profissionais com deficiência terem bom desempenho no trabalho, mas também para os gestores que receberão esses profissionais. O autor também destaca a necessidade de discussões mais amplas sobre a inclusão de pessoas com deficiência na empresa. Apoiamos essas alegações, porque uma das atribuições dos Recursos Humanos deve ser a promoção de tais diálogos, envolvendo não apenas a liderança, mas também colegas do setor, para que a recepção e a cooperação possam ocorrer com mais maturidade, em relação aos profissionais com deficiência.

Esta breve revisão da literatura sobre 0 assunto mostra que existem estudos sendo conduzidos, como uma tentativa de entender contextos específicos com seus desafios e possibilidades. Em geral, há uma proposição de mais diálogos envolvendo pessoas com deficiência, autoridades públicas locais, empresas e sociedade, para que a inclusão dessa população possa ocorrer de maneira produtiva para eles e para as demais instituições envolvidas.

\subsection{A experiência de pessoas com deficiência}

A importância da vida na comunidade e como parte dela para todas as pessoas com deficiência sustenta o artigo 19 da Convenção das Nações Unidas sobre os Direitos das Pessoas com Deficiência (European Coalition for Community Living, 2009) e é apoiado por descobertas sobre a exclusão social de pessoas com deficiência em relatórios como os divulgados pelo Conselho Nacional de Pessoas com Deficiências e Cuidadores da Austrália (2009) e pelo Instituto de Pesquisa Econômica e Social da Irlanda (Gannon e Nolan, 2005). Relatórios como esses descrevem consistentemente os baixos níveis de educação, renda e emprego das pessoas com deficiência. Emerson e Hatton (2007) também identificam a ligação entre deficiência, exclusão social e saúde precária. Ambos os relatórios também indicam limites em aspectos mais amplos da participação na vida da comunidade e da sociedade. Por exemplo, o relatório irlandês descreve que as pessoas com deficiência têm menos probabilidade de ingressar em um clube, menos provavelmente conversará com os vizinhos e menos propenso a sair para se divertir. O relatório australiano também descreve que ainda hoje muitas pessoas com deficiência não podem acessar instalações públicas e são excluídas de caminhos de vida dados como garantidos, como ir ao jardim de infância e escolas, seguido pelo trabalho, estabelecer a própria casa, passar férias, casamento etc. 


\title{
RECIMA21 - REVISTA CIENTÍFICA MULTIDISCIPLINAR
}

\author{
GESTÃO INCLUSIVA DA PESSOA COM DEFICIÊNCIA NO \\ AMBIENTE DE TRABALHO \\ Evandro Ferigato
}

\subsection{Três fatores que contribuem para a experiência de exclusão social.}

1. Crenças e valores sociais: Não é necessário levantar muito profundamente 0 tecido de nossa sociedade para descobrir crenças profundamente arraigadas sobre pessoas com deficiência. A experiência de ser percebido e tratado como o 'outro' é capturado por Wolfensberger (Race,1999), quando descreve dez papéis de desvio, também entendidos como estereótipos, nos quais as pessoas com deficiência provavelmente serão lançadas. Esses papéis negativos, como 'criança eterna', 'doente', 'ameaça', 'fardo' e 'menos que humano' são expressões de rejeição da humanidade compartilhada de pessoas com deficiência. Eles não estão apenas profundamente enraizados em nossa sociedade agora, mas também em nossa história. É altamente provável que essas circunstâncias continuem no futuro, pois esse processo de "outro" está vinculado aos nossos valores, e as pessoas com deficiência incorporam muitas coisas que nossa sociedade ocidental valoriza negativamente: as pessoas com deficiência são vistas como pouco atraentes, improdutivas, dependentes e afastadoras da vida confortável dos outros. Percepções de pessoas com deficiência como menos dignas levam as pessoas a serem tratadas como menos dignas;

2. Como os sistemas de serviço normalmente funcionam: Outro conjunto de lutas para pessoas com deficiência e, frequentemente, suas famílias, se relaciona com o modo como nossos sistemas de serviço normalmente operam. As formas dominantes de serviço continuam a serem construídas e baseadas em grupos, como evidenciado por casas de grupo, centros de dia e abrigos oficinas. Embora eles possam estar localizados nos bairros da comunidade, as pessoas não estão conectadas à vida comunitária local ou estão apenas superficialmente presentes na vida comunitária, como visitas a lojas e parques locais. As pessoas com deficiência podem ter maior presença na comunidade do que nos dias de instituições nos arredores da cidade, no entanto, os padrões comuns são de que eles não têm participação na vida da comunidade e não têm a rede de relacionamentos que outros consideram certa. A revisão de literatura de Lemay em 2007 indica que não eram apenas as redes sociais de pessoas com deficiência menores que as redes de pessoas sem deficiência, mas que essas redes eram compostas principalmente por outros destinatários de serviços e funcionários remunerados, mesmo que as pessoas estivessem em residências comunitárias;

\section{Necessidades de identidade e} imperativos econômicos: Além disso, são muitas as forças para manter as pessoas com deficiência em estados excluídos. Isso inclui o tribalismo (que os humanos se definem por 'quem não são'; os limites de quem estão 'dentro' são definidos por quem é determinado como 'fora') e os valores da sociedade, como o individualismo. Além disso, muitas economias ocidentais agora dependem de grupos desvalorizados: são esses grupos que fazem o trabalho que outros com status valorizado não realizam, e são eles que são uma fonte de 


\section{RECIMA21 - REVISTA CIENTÍFICA MULTIDISCIPLINAR}

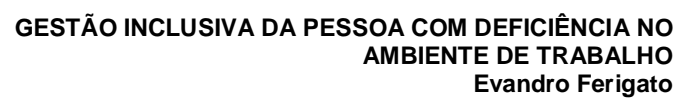

emprego (Kitchin, 1998; Race,1999) para muitos que trabalham no que é frequentemente chamado de 'indústria da deficiência'.

O que é desejável na vida das pessoas com deficiência, para o qual o termo "inclusão social" é comumente usado 'Desejamos um lugar dentro da comunidade! Este lugar não é apenas um lugar para deitar nossas cabeças, mas um lugar que traz conforto e apoio com a vida diária, amizade, trabalho significativo, recreação emocionante, renovação espiritual, relacionamentos nos quais podemos ser nós mesmos livremente com os outros. E dessas grandes coisas podem florescer. (Conselho Nacional de Pessoas com Deficiência e Cuidador, 2009: viii). Essa citação capta pungentemente $\mathrm{o}$ que se entende pelo termo 'inclusão social' e outros termos como 'vida comunitária', 'vida comum', 'vida típica' e 'vida rica em significado'. Ocasionalmente, há relutância em considerar que poderia haver uma única noção de "típico" ou "comum", que é compreensível, dada a amplitude das características e preferências humanas. No entanto, se considerarmos vidas típicas relevantes para gênero, cultura e idade, por exemplo, na sociedade ocidental, os adultos geralmente esperam ter um lar, oportunidades de contribuição, uma família ou um pequeno grupo íntimo, uma rede social mais ampla, coisas que dão propósito, boa saúde, voz sobre as coisas importantes da vida, segurança, sistema de crenças, oportunidades para aprender e desenvolver as habilidades e habilidades, et al 1996). Flynn e Aubry (1999) fizeram uma extensa revisão da literatura, incluindo literatura de pesquisa, sobre integração e pessoas com deficiência e descobriram que a definição de Wolfensberger era 'o mais rico e mais útil' (p296). Wolfensberger (1998) usa o termo ' integração social pessoal e participação social valorizada e define 'como participação adaptativa de uma pessoa socialmente desvalorizada em uma quantidade culturalmente normativa de contatos, interações e relacionamentos, com cidadãos comuns, em atividades típicas e em ambientes físicos e sociais com valor social '(p123). Essa definição ajuda a entender que a presença física na vida da comunidade é apenas um elemento e que os outros elementos são a participação da comunidade e uma série de relacionamentos com pessoas que têm um status valorizado. Se as pessoas estão apenas presentes na comunidade, elas não experimentam integração social, de acordo com esta definição. A falta de uma variedade de relacionamentos significa que as pessoas provavelmente não experimentarão pertencer a uma rede de amigos e conhecidos.

\subsection{Desafios para os líderes}

Como indica a literatura mais ampla sobre exclusão social, as causas da exclusão social podem residir ou devido a problemas "dentro" do individual ou devido a barreiras estruturais. No que diz respeito à visão anterior e às pessoas com deficiência, os limites à inclusão social que se entende serem por causa da capacidade limitada no indivíduo são vistos em esforços que tiveram um foco de reabilitação ou treinamento (por exemplo, White et al 2010). Responder a questões de exclusão social no 


\section{RECIMA21 - REVISTA CIENTÍFICA MULTIDISCIPLINAR}

\section{GESTÃO INCLUSIVA DA PESSOA COM DEFICIÊNCIA NO AMBIENTE DE TRABALHO Evandro Ferigato}

nível de políticas e sistemas envolvem frequentemente processos para identificar os grupos marginalizados, consulta e facilitação do acesso aos serviços, como em um relatório de Brackertz e Mereduth (2008).

Esses esforços são em grande parte insuficientes para atingir o espírito de inclusão social descrito na citação do Conselho Nacional de Pessoas com Deficiência e Cuidadores ou os elementos de integração social e participação valorizada, conforme definido por Wolfensberger. São necessários esforços conjuntos dos líderes para enfrentar os desafios de maneira real, ao lado de pessoas com deficiência e até na ausência de políticas positivas ou de sistemas facilitadores. Não é suficiente simplesmente ter mais serviços envolvidos na vida das pessoas com deficiência; o que é importante é o que esses serviços fazem e o que os líderes de nossas comunidades e serviços fazem.

Os líderes podem ser encontrados no sistema de atendimento humano para pessoas com deficiência, nas próprias pessoas com deficiência, nas famílias e nas comunidades. A luta pela inclusão social exige que aqueles que ocupam cargos de liderança enfrentem os cinco desafios a seguir:

1. Desenvolva um profundo senso do que realmente significa o conceito de 'inclusão social': Conforme identificado anteriormente, o termo 'inclusão social' é descrito como problemático na literatura mais ampla, pois é visto como a antítese da exclusão social. Isso também é problemático na vida das pessoas com deficiência. Muitos que buscam inclusão social na vida das pessoas com deficiência assumem um entendimento comum sobre o que isso significa e quais são os objetivos; eles geralmente falam sobre 'vidas comuns' e vida comunitária. Na prática, o termo foi cooptado. Isso é visto em um exemplo não incomum de um serviço que agrupa pessoas com deficiência, as leva em um ônibus pertencente a um programa com base em centros e se refere a ele como um programa de inclusão porque está localizado em a comunidade. Essa prática contrasta com um serviço que apoia indivíduos a realizar atividades comuns com cidadãos não deficientes, o que também se refere ao seu programa como inclusão.

Um resultado disso é que há alegações de que as pessoas com deficiência são incluídas socialmente, quando fica claro que não. A questão esmagadora é que uma proporção significativa de pessoas com deficiência permanece marginalizada em nossas comunidades. Somente se os líderes tiverem a sensação de que a inclusão social se refere a muito mais que a presença da comunidade, está em um caminho com potencial. Isso requer uma apreciação dos limites dos termos 'exclusão social' e 'inclusão social' e uma amplitude e profundidade do termo 'inclusão social', mais bem capturado na definição de integração social pessoal e participação social valorizada de Wolfensberger.

Fundamentalmente, este é um desafio para ' imaginando melhor '(Kendrick, 2002). Kendrick nos lembra de que imaginar uma alternativa pode ajudar o progresso para outra realidade. Outros se referiram a isso como sonhar ou imaginar. Isso requer uma orientação para as pessoas com deficiência que enxergam 


\section{RECIMA21 - REVISTA CIENTÍFICA MULTIDISCIPLINAR}

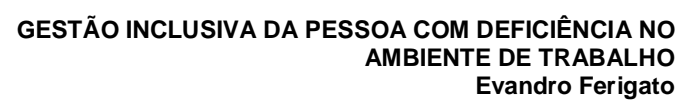

as boas qualidades, as capacidades e 0 potencial de cada pessoa. Requer uma capacidade de se desligar do papel singular de gerente ou trabalhador ou membro da família e ficar no lugar da parte vulnerável e usá-la como um filtro para todas as decisões que afetam a pessoa vulnerável. É uma tarefa dos líderes despertar o senso de possibilidade nas pessoas ao seu redor e ajudar a mudar a mentalidade das expectativas baixas e a confiança no grupo tradicional e nas respostas baseadas em construção. As necessidades podem ser entendidas não como barreiras à participação, mas antes como pistas para as condições com maior probabilidade de trazer o melhor para cada pessoa. Os desejos por uma vida melhor, mais inclusiva e participativa podem ser vistos não como uma expressão fútil da auto ilusão da pessoa, mas como algo a ser levado a sério.

Isso exige que os líderes nos serviços compreendam os modelos tradicionais que podem falar a retórica da inclusão social de modelos que possuem características como oferecer caminhos individualizados e possibilitar a participação através de coisas como apoiar as pessoas em papéis e relacionamentos valiosos. O desafio para os líderes é aprofundar sua compreensão e visão para inclusão social e ser astuto em reconhecer à retórica e os limites dos modelos tradicionais;

2. Confronte as questões de valores: Gallagher (2001) identifica que a inclusão social é vista como uma questão moral ou uma questão a ser decidida com base em evidências empíricas. Ela argumenta que argumentos empíricos contra a inclusão não são neutros em relação aos valores e, de fato, se baseiam em ideologias (imprecisas e inúteis). Essas ideologias incluem uma aceitação da precisão da rotulagem e categorização e seu potencial para determinar as capacidades das pessoas com deficiência; aceitação das funções de classificação das escolas; aceitação da suposição de que as salas de aula segregadas são protetoras; e a negação de que as decisões sobre a forma, o tamanho e as operações das salas de aula regulares foram baseadas em suposições que poderiam ser falsas. "Ela conclui que não é possível considerar apenas argumentos empíricos; que as ações para (ou se afastem) da inclusão social devem começar com" uma luta de consciência 'sobre que tipo de mundo está criando (Gallagher, 2001: 651).

Argumentos que pretendem só ter uma base econômica (por exemplo, a inclusão social é mais cara ou muito cara), uma base de recursos humanos (os funcionários não são treinados) ou uma base de capacidade humana (por exemplo, a comunidade nunca aceitará pessoas e que a comunidade é perigosa) também tem uma base de valores.

É essencial que os líderes se envolvam em perguntas sobre valores. Duggan (2005: 36) fez um convite para contemplar nossa humanidade compartilhada 'e deu encorajamento': Por favor, tente fazer o seu melhor para ver o passado e através da minha deficiência. Pois é quando esse momento chega - e não antes! - que possamos nos encontrar como seres verdadeiramente humanos '(Duggan, 1999: 38).

Foram emitidos cuidados quanto à adoção superficial de uma base de valores. 


\section{RECIMA21 - REVISTA CIENTÍFICA MULTIDISCIPLINAR}

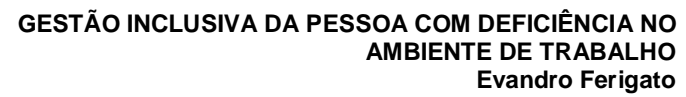

Kendrick e Sullivan (2009) advertem contra 'um slogan político conveniente e confuso' (p67). Armstrong (2007) adverte contra um abraço ideológico da noção de uma sociedade inclusiva que é expressa em mantras como ' aceitação da diversidade 'e' nossa sociedade deve ser inclusiva' Ele baseou essa cautela no domínio contemporâneo do modernismo, que eleva o interesse próprio acima do interesse dos outros ou do coletivo. Isso é tão forte na sociedade ocidental que é altamente improvável facilitar a inclusão social fácil ou automática de pessoas com características negativamente valorizadas. Além disso, é ineficaz simplesmente reivindicar os 'direitos' das pessoas a serem incluídas, pois, sem os valores subjacentes úteis, os direitos não serão concedidos ou serão concedidos de maneira espirituosa. O desafio é que os líderes explorem seus próprios valores e ajudem as pessoas a seu redor a fazer o mesmo, para que esses valores conscientes possam inspirá-los e levá-los à ação, e para que a ação seja coerente com seus valores;

3. Tenha consciência do que a comunidade é ensinada através das ações de serviços: Kitchin (1998) afirma que as pessoas com deficiência não são apenas "mantido" em seu lugar por diferenciais de poder, despreocupação e ignorância, mas também pelos ambientes físicos que comunicam aos espectadores que eles precisam estar um com o outro e não pertencem à vida comum. Isso é tão forte que, quando as pessoas com deficiência são vistas no ambiente físico cotidiano, elas são frequentemente consideradas 'fora de lugar'. Além disso, pessoas com um status valioso aceitam isso como natural e bom senso e normalmente não o questionam.

Armstrong (2007) nomeou isso como a baixa consciência que os seres humanos têm por sua própria capacidade de desvalorizar os outros.

Lee (2007) destaca que a comunidade é testemunha do que os serviços e prestadores de serviços fazem. Portanto, cidadãos com noções preconcebidas sobre pessoas com deficiência os confirmarão testemunhando as maneiras pelas quais as pessoas são faladas e escritas sobre e para, o tamanho dos grupos em que as pessoas são convocadas, os grupos são formados por pessoas com deficiência, para que os ambientes físicos em que as pessoas passam seu tempo e as atividades realizadas lá possam não ser apropriados à idade ou propícios ao desenvolvimento de capacidades.

Lee ainda articula que os serviços ensinam a comunidade sobre o local e o valor das pessoas com deficiência por meio de ações de serviços, tais como serviços que mediam qualquer envolvimento entre uma pessoa com deficiência e um cidadão comum e utilizam processos como processos de aprovação, treinamento e registro e, portanto, dão a impressão de que apenas um serviço profissional pode atender às necessidades de alguém com deficiência. Combinando essa ênfase ao 'apenas cuidado profissional', os serviços agem como se a comunidade tivesse medo de pessoas com deficiência, o que transforma a equipe em guardas.

O desafio é que os líderes criem oportunidades e arranjos de apoio que não reforcem as baixas expectativas pré-concebidas 


\section{RECIMA21 - REVISTA CIENTÍFICA MULTIDISCIPLINAR}

\section{GESTÃO INCLUSIVA DA PESSOA COM DEFICIÊNCIA NO AMBIENTE DE TRABALHO Evandro Ferigato}

sobre as pessoas com deficiência e que estendam as mentes dos cidadãos para ver a possibilidade de presentes, pontos fortes e contribuições das pessoas com deficiência para a vida comunitária. Assim, é quando os indivíduos com deficiência são apoiados em papéis valiosos, em lugares comuns, fazendo coisas comuns com cidadãos comuns, que os cidadãos provavelmente terão suas ideias preconcebidas confrontadas. Essa é uma mudança de atitude em nível de base;

4. Transformar o papel dos serviços e trabalhadores: Esse desafio refere-se à necessidade de os líderes liderarem mudanças e inovações em serviços e sistemas humanos e exige que os líderes venham de uma sólida base teórica e prática muito diferente da base dos serviços tradicionais.

Por décadas e mais, o sistema de serviço é tal que o paradigma dominante é aquele em que as pessoas com deficiência estão em comunidade, mas não em comunidade. Lemay (2006) ressalta que, enquanto muitas pessoas com deficiência vivem e se deslocam em comunidades comuns, elas não possuem os níveis de participação e redes sociais que seriam esperados.

O'Brien (1999) observa como diferentes casas de grupo são de casas reais; quão diferentes são as oficinas protegidas nos locais de negócios e quão diferentes as escolas especiais são das escolas regulares. Jackson (2008) e Lee (2008) identificam algumas das maneiras pelas quais as casas de grupo não são típicas: as características físicas, como o tamanho da casa, a presença de uma sala dos funcionários, o agrupamento de indivíduos que compartilham pouco além de portadores de deficiência, servem para reforçar ideias préexistentes, sobre a 'alteridade' das pessoas com deficiência e levar a comportamentos de rejeição pelos bairros locais.

Tradicionalmente, as pessoas com deficiência são 'colocado em' serviços (O'Brien et al 2001). Os serviços se tornam receptáculos para as pessoas com deficiência: se as pessoas têm necessidades, as comunidades, famílias, pessoas com deficiência e os serviços esperam que o serviço (e apenas um serviço) atenda a essas necessidades.

Lemay (2006) observa que o isolamento social está relacionado à escassez de papéis sociais valorizados na vida das pessoas que, de outra forma, seriam caminhos naturais para os relacionamentos. Pode-se deduzir que é provável que essa situação ocorra se os trabalhadores de apoio se limitar principalmente aos cuidados pessoais e às tarefas domésticas e, assim, se tornarem, em grande parte, cuidadores.

A evolução dos serviços, sistemas e o papel dos profissionais de serviço devem estar voltados para um paradigma em que os serviços facilitam 0 atendimento das necessidades, em que o papel do serviço é fornecer os apoios para permitir que as pessoas participem ativamente de casa e da vida vizinha, trabalho, paixões e interesses em lazer, espiritualidade e a vida social associada em todos esses domínios. Isso 


\section{RECIMA21 - REVISTA CIENTÍFICA MULTIDISCIPLINAR}

sinaliza uma mudança do papel do trabalhador como cuidador, protetor e mediador para um facilitador de oportunidades, guia para estilos de vida e relacionamentos comuns, mentor e incentivador para aprender coisas novas e intérprete dos modos da comunidade. Isso indica que uma das coisas muito úteis que os serviços podem estar fazendo para apoiar as pessoas na inclusão social é apoiá-las a desempenhar papéis valiosos, como dona de casa, vizinha, funcionário, assim, esse desafio é sobre mudança, transformação, evolução e inovação.

Kendrick e Sullivan (2009: 71) apontam que 'um padrão mais comum de mudança é a evolução de exemplos positivos do que está sendo buscados, decorrentes de instâncias muito pequenas de pioneirismo social e experimentação'. Eles estão descrevendo uma maneira potente de que a mudança pode acontecer: experimentar coisas novas e aproveitar os exemplos positivos;

5. Use o conhecimento baseado na teoria: O desafio da liderança é também encontrar as teorias e abordagens que ajudarão o trabalho de inclusão social. As teorias que explicam a desvalorização social, as experiências de exclusão social e os caminhos para papéis valorizados, como a valorização de papéis sociais (Wolfensberger, 1998; Race, 1999) são altamente relevantes e úteis. O poder de apoiar as pessoas em papéis valiosos é que essa dinâmica não apenas permite que as pessoas participem de papéis de participação e contribuição, com maiores oportunidades de relacionamento, mas também influencia a maneira como uma pessoa com deficiência é percebida.

Os líderes também devem procurar estruturas e abordagens sobre como trabalhar na e com a comunidade. O trabalho com cidadãos comuns que os ajudam a resistir ao impulso de rejeitar pode ser derivado de abordagens de desenvolvimento comunitário. $\mathrm{O}$ que não se entende aqui é o desenvolvimento comunitário que leva ao desenvolvimento de serviços e ao uso de trabalhadores remunerados. O ramo mais relevante do desenvolvimento da comunidade é exemplificado em Westoby e Owen (2009), que apresentam uma estrutura prática útil que envolve 'tipos particulares de comunicação e ação que constroem comunidades' ( $p 1)$. Isso resulta em uma rede de relacionamentos, em que 0 trabalhador pago não é o pivô central desses relacionamentos.

$O$ trabalho em torno da ponte e da ligação de capital social também é altamente relevante. Knudsen (2007) cita Putnam ao descrever o capital social como 'os laços sociais, conexões, redes e normas das quais os indivíduos e coletividades se beneficiam'. O vínculo acontece entre pessoas "semelhantes", como aproximar pessoas socialmente isoladas. O benefício é que as pessoas são reunidas através de uma situação ou interesse compartilhado e, assim, as pessoas podem se sentir menos sozinhas. O risco, no entanto, é que isso serve para isolar grupos com base na homogeneidade, e eles podem ficar presos em um ciclo de situação compartilhada. É o que acontece nos serviços congregados para pessoas com deficiência. A ponte entre capital 


\section{RECIMA21 - REVISTA CIENTÍFICA MULTIDISCIPLINAR}

GESTÃO INCLUSIVA DA PESSOA COM DEFICIÊNCIA NO AMBIENTE DE TRABALHO Evandro Ferigato

social existe quando há conexões desenvolvidas entre uma gama de pessoas marginalizadas e não marginalizadas, para que as pessoas tenham acesso a uma variedade de informações e recursos. É essa forma de capital social que será útil para a inclusão social de pessoas com deficiência.

\subsection{Quais podem ser os atributos de liderança}

Um trabalho minucioso e ponderado pela inclusão social é mais provável quando os líderes mostram coerência entre valores, pensamento e ação. Liderança autêntica é mais provável quando cinco condições estão presentes;

1. Os líderes têm uma base moral e ética: Os valores e crenças que o líder mantém em um nível profundamente pessoal refletem tais crenças que a humanidade é compartilhada entre todos os seres humanos. As qualidades do coração incluem compaixão e um profundo sentimento pela situação das pessoas com deficiência que são excluídas com base em diferenças negativas.

Qualidades como esperança, otimismo e coragem estão presentes.

Isso é necessário porque, ao trabalhar pela inclusão social, o líder trabalha primeiro contra a inclinação natural dos seres humanos a rejeitar e excluir e, portanto, trabalha de maneira contrária aos grupos dominantes em nossa sociedade.

Segundo, o líder está trabalhando contra as forças da nossa sociedade que mantêm as pessoas como 'outras'. A base moral e ética é uma base para o que acontece no nível do conhecimento;

2. Existe uma combinação de clareza conceitual, discernimento, conhecimento e sabedoria: A utilização de uma sólida base teórica e prática, como a recomendada anteriormente, baseia-se nos valores e na ética do som. Um sem o outro será insuficiente.

Turnbull (2009) sugere a importância da ação baseada na sabedoria para facilitar a inclusão social, por estarem sintonizados com valores, visão e contexto; utilizando e avaliando o conhecimento, usando o discernimento para planejar as próximas etapas e executar ações que incluem aprendizado de ação e conexões com aliados;

3. Existe um relacionamento autêntico com pessoas com deficiência e familiares: Isso fornece uma âncora à realidade da rejeição e exclusão na vida das pessoas e fornece um estímulo à ação. Sem essa proteção é difícil para um líder estar atento ao que está em jogo para as pessoas com deficiência. Com esse amparo, mesmo que seja difícil testemunhar a exclusão social e seus impactos, é mais provável que o líder queira fazer uma diferença poderosa e inspirar outros a fazê-lo também;

4. Há uma apreciação da história: Os sistemas de serviço ao longo do tempo estão repletos de 'novas ideias' e 'novos serviços' que são, na realidade, uma recriação de respostas de tempos passados. O respeito pela história leva um líder a perceber que nem tudo que é considerado novo é de fato novo e certamente não é necessariamente bom ou útil. Por exemplo, edifícios residenciais continuam a ser 


\section{RECIMA21 - REVISTA CIENTÍFICA MULTIDISCIPLINAR}

GESTÃO INCLUSIVA DA PESSOA COM DEFICIÊNCIA NO AMBIENTE DE TRABALHO Evandro Ferigato

construídos e podem ser chamados de 'aldeias', mas na verdade são repetições do contexto doméstico do grupo que está em evidência há décadas;

5. Os líderes depositam sua fé e esforços em coisas que provavelmente trarão dividendos: É altamente improvável que melhores processos de avaliação, melhores processos de planejamento, mais dinheiro, melhor treinamento façam as diferenças reais $e$ duradouras na vida das pessoas com deficiência. Nem uma dependência excessiva de padrões e auditorias baseadas em conformidade como medidas de qualidade. As principais medidas para a qualidade precisam ser o que as pessoas com deficiência experimentam no dia-adia e, em termos de inclusão social, até que ponto elas participam da vida da comunidade em uma variedade de papéis e relacionamentos. É mais provável que as soluções estejam nas qualidades baseadas em valores na liderança e na equipe, nos fundamentos teóricos do trabalho e no trabalho real na comunidade.

\section{MÉTODO DE PESQUISA}

\subsection{Problema da Pesquisa}

A importância do emprego não pode ser subestimada. Sendo um empregado, colega ou colaborador é um papel social fundamental que depende de estar na força de trabalho com salários equitativos. Com esses critérios, as barreiras podem ser removidas para permitir que as pessoas com deficiência sejam verdadeiras cidadãs do mundo e ativamente incluídas na sociedade. Embora exista legislação para derrubar as barreiras ao emprego, ainda existem várias objeções à contratação de pessoas com deficiência.

\subsection{Tipo de Pesquisa}

Para o desenvolvimento desta pesquisa, realizamos uma revisão da literatura sobre as principais discussões sobre a inclusão de pessoas com deficiência e os desafios da Gestão de Recursos Humanos nos principais periódicos de Engenharia de Produção, nos anais da ENEGEP (Convenção Nacional de Produção Engenharia), em periódicos de Administração de Empresas e Psicologia Organizacional e outros interessados no assunto. Foi possível deduzir que ainda é um assunto pouco discutido na literatura, sob essa perspectiva, classifica-se esta pesquisa como o de caráter exploratório, com o objetivo de aprofundar as ideias sobre o objeto de estudo, sustentado na pesquisa bibliográfica, no qual os dados foram buscados em livros, revistas e internet que serão descritas no decorrer deste.

\subsection{Justificativa}

Simonelli \& Camarotto (2011) podem ajudar com informações nesse contexto, uma vez que a proposição dos autores permite ajudar os gestores a identificar os trabalhos que podem ser desempenhados por pessoas com deficiência, uma vez que o diálogo entre a gerência e profissionais experientes nesse tipo de inclusão pode resultar em ações mais eficazes. 


\title{
RECIMA21 - REVISTA CIENTÍFICA MULTIDISCIPLINAR
}

\author{
GESTÃO INCLUSIVA DA PESSOA COM DEFICIÊNCIA NO \\ AMBIENTE DE TRABALHO \\ Evandro Ferigato
}

Carvalho-Freitas (2009) propõe discussões mais amplas sobre deficiência, nas empresas. Futuras discussões em instituições como sindicatos e outras instituições da cidade, para que a população busque descobrir e manter-se informada com os direitos de inclusão de pessoas com deficiência no local de trabalho, além de promover um debate mais amplo para ações práticas para que essa inclusão ocorra.

\section{RESULTADOS E DISCUSSÕES}

Observamos em nossa análise que muitos gerentes relatam não ter certeza de como tomar medidas disciplinares ou demitir um trabalhador com deficiências que não atenda às expectativas de desempenho, e eles podem estar preocupados com as consequências legais do manuseio inadequado desse processo (Lengnick-Hall et al., 2008 ; Kaye et al., 2011 ; ver também Gaunt \& Lengnick-Hall, 2014). No entanto, para todos os funcionários, independentemente do status de incapacidade, as organizações devem ser proativas no gerenciamento (e documentação, conforme necessário) dos problemas de desempenho, fornecendo treinamento ou acomodações, quando relevante, e fornecendo expectativas claras de desempenho. Se surgirem dificuldades de desempenho, o feedback regular e imediato é importante, independentemente do status da incapacidade. Gröschl (2013) mostra os benefícios do feedback imediato que utilizou exemplos factuais e objetivos quando os funcionários com deficiência exibiram baixo desempenho. É importante ressaltar que a rescisão por desempenho ruim pode ser considerada discriminatória se o treinamento ou as acomodações adequados não tiverem sido fornecidos.

Os funcionários com deficiência relatam que a ação legal ocorre normalmente após outras tentativas de recebimento de acomodações razoáveis falharem e que as ações legais são o resultado de uma falta de conhecimento em nível organizacional sobre como melhor apoiar as carreiras de pessoas com deficiência (Wilson-Kovacs et al., 2008). A ação legal é um último recurso que talvez seja afetado pela adesão de alguns gerentes a falsos estereótipos que veem as pessoas com deficiência como habilitadas ou solicitando tratamento especial (Kaye et al., 2011). De fato, alguns argumentaram que a imprecisão inerente às leis e requisitos de acomodação podem contribuir para esse estereótipo (Wilson-Kovacs et al., 2008). Além disso, os gerentes geralmente relatam lacunas de conhecimento sobre as melhores práticas de acomodação e o entendimento da experiência da deficiência (Kaye et al., 2011 ; Wilson-Kovacs et al., 2008). Portanto, é importante que gerentes e pessoas com deficiência trabalhem em acomodações como parceiros e aliados. As acomodações são mais eficazes quando todas as partes trabalham juntas como verdadeiros parceiros e quando estratégias alternativas são adotadas se as tentativas iniciais de acomodação não tiverem êxito.

Os empregadores costumam ter medo de litígios, algo que pode ser particularmente preocupante para pequenas organizações, que não se beneficiam do apoio prestado por um 


\section{RECIMA21 - REVISTA CIENTÍFICA MULTIDISCIPLINAR}

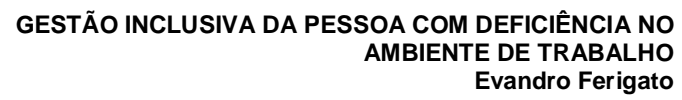

departamento jurídico. Os empregadores são proativos em termos de compreensão do contexto jurídico, como visitando sites que fornecem informações sobre leis trabalhistas em sua jurisdição e, mais importantes, concluindo cursos de treinamento pessoalmente ou online demonstram boa vontade e garantem que os gerentes estejam cientes das práticas adequadas. Os proprietários de pequenas empresas também podem se beneficiar da associação de redes ou sociedades de negócios dedicadas à inclusão de trabalhadores com deficiência. A capacidade de aprender com organizações de colegas (por exemplo, tamanhos similares, indústrias), compartilhar histórias de sucesso e aprender com as falhas uns dos outros pode ser particularmente reconfortante para os pequenos empresários.

A pesquisa legal sobre os fatores que tornam os trabalhadores com deficiência mais (ou menos) propensa a processar seus empregadores forneceria orientações úteis em termos de como evitar ações judiciais. Pesquisas semelhantes na área médica descobriram que os médicos que se desculpam com os pacientes (ou suas famílias) por seus erros médicos reduzem realmente a probabilidade de ações judiciais por negligência médica, mesmo admitindo responsabilidade (Ho \& Liu, 2011). No contexto do emprego seria útil determinar se algum aspecto do comportamento de gerentes ou colegas de trabalho (por exemplo, linguagem depreciativa, exclusão) está desproporcionalmente associado a ações civis.
Pesquisas de arquivo que examinam decisões legais seriam especialmente úteis.

\section{CONCLUSÃO}

Trabalhadores com deficiência formam um dos maiores grupos de diversidade no local de trabalho (Hyland \& Rutigliano, 2013). Devido ao alto nível de desemprego entre as pessoas com deficiência, muitos argumentam que eles são insuficientemente utilizados como um pool de mão-de-obra e que os empregadores desejam recrutá-lo para lidar com a escassez de mão-de-obra causada por mudanças demográficas à medida que os baby boomers se aposentam e são substituído por menos novos ingressantes na força de trabalho (Lengnick-Hall et al., 2008 ; Kruse et al., 2010 ; Schur et al., 2014).

No entanto, apesar dos avanços nas práticas de diversidade e inclusão no local de trabalho, a entrada e progressão de pessoas com deficiência na força de trabalho permanecem problemáticas. De fato, LengnickHall et al. (2008) argumentam que "a maioria dos empregadores mantém crenças estereotipadas não suportadas por evidências de pesquisa" ( $p$. 255). Como essas crenças amplamente difundidas são frequentemente alimentadas pela falta de informações, fornecemos respostas baseadas em evidências para 11 preocupações expressas pelos gerentes sobre o emprego de pessoas com deficiência. A análise baseou-se em evidências empíricas, apoia práticas de emprego inclusivas que vão além da mera conformidade legal. De fato, a literatura empírica 


\section{RECIMA21 - REVISTA CIENTÍFICA MULTIDISCIPLINAR}

revisada neste artigo revela que, ao longo do ciclo de emprego, os trabalhadores com deficiência não devem ser motivo de preocupação para os empregadores. Em vez disso, seria sensato que os empregadores fizessem uso dessa mão-de-obra subutilizada, dado o retorno dos investimentos proporcionados por práticas organizacionais inclusivas.

Neste artigo, evidenciou-se uma visão geral das preocupações expressas pelos gerentes sobre a contratação de trabalhadores com deficiência, bem como usamos a literatura atual em administração, recursos humanos, psicologia industrial / organizacional, ciências da reabilitação e saúde pública para examinar a validade de essas preocupações. No trabalho futuro, as preocupações ao longo do ciclo de emprego podem ser refletidas, concentrando-se na perspectiva dos funcionários. Por exemplo, as preocupações expressas pelos gerentes em torno das acomodações são do ponto de vista dos funcionários com deficiência, preocupações com o fornecimento adequado de suporte. Da mesma forma, as preocupações com o desempenho andam de mãos dadas com o fornecimento de feedback preciso e oportuno do ponto de vista dos funcionários.

Embora os hábitos humanos pessoais e sociais que levam à exclusão social estejam profundamente arraigados, existe a possibilidade de transformação de nossos serviços e comunidades. Certamente, algumas das preocupações expressas pelos gerentes, como as que envolvem a integração organizacional, podem ser relevantes para outros grupos estigmatizados no local de trabalho. Outros, como as preocupações relacionadas aos custos de acomodação ou comportamentos de segurança, não são. Manteve-se o foco nas deficiências, o que nos proporcionou uma maior oportunidade para uma análise aprofundada. As respostas baseadas em evidências às preocupações dos gerentes, também forneceram aos gerentes recomendações práticas e recursos adicionais que podem ser úteis se procurarem apoiar os trabalhadores com deficiência durante todo o ciclo de emprego.

Por fim, algumas sugestões para pesquisas adicionais que abordem mais essa temática se fazem necessário para complementar o estudo e reforçar a importância dessa problemática exposta.

$\mathrm{O}$ artigo procurou fornecer um ponto de partida para uma consideração das experiências dos trabalhadores com deficiência; dado o considerável potencial desse segmento da força de trabalho, devendo-se nos esforçar para alavancar suas habilidades.

\section{REFERÊNCIAS}

Armstrong J (2007) 'Desejando uma estrela' - os problemas e soluções de confiar em uma 'sociedade inclusiva' para promover e proporcionar uma vida melhor para as pessoas. The SRV Journal 2 ( 2) 9-16.

Ávila-Vitor, MRC e Carvalho-Freitas, MN (2012). Valores organizacionais e concepções de deficiência: uma percepção de pessoas 


\section{RECIMA21 - REVISTA CIENTÍFICA MULTIDISCIPLINAR}

\section{RECIMA?}

incluídas. Psicologia (Conselho Federal de Psicologia) , 32 (4), 792-807.

Brackertz N e Mereduth D (2008) Inclusão social do difícil de alcançar: consulta comunitária e difícil de alcançar. Governo local, perfil social e infraestrutura cívica. Hawthorn: Instituto Swinburne de Pesquisa Social.

Brasil (2013). Estatuto da pessoa com deficiência. Brasília: Secretaria de Edição e Publicações. Coordenação de Edições Técnicas.

Brasil. Ministério das Relações Exteriores. (1983). Decreto o 129, de 22 de maio de 1991. Promulga a Convenção no 159, da Organização Internacional do Trabalho - OIT, sobre Reabilitação Profissional e Emprego de Pessoas Deficientes. (p. 9783). Brasília, DF: Diário Oficial da República Federativa do Brasil.

Brasil. Presidência da República. Subchefia da Casa Civil para Assuntos Jurídicos (2015, 7 de julho). Lei no 13.146, de 6 de julho de 2015. Institui a Lei Brasileira de Inclusão da Pessoa com Deficiência (pp. 1-34). Brasília, DF: Diário Oficial da República Federativa do Brasil.

Brendle, JL , RH Lock e LA Smith . 2019 . " Indicadores de trabalho de qualidade para indivíduos com dificuldades de aprendizagem ". Journal of Vocational Education \& Training 71

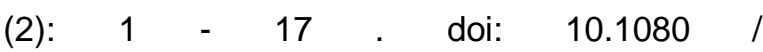
13636820.2018.1472137Carvalho-Freitas, $\quad M N$ (2009) Inserção e gerenciamento de trabalho de pessoas com eficiência: um estudo de caso. Revista de

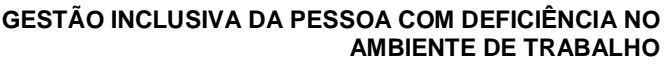
Evandro Ferigato

Administração Contemporânea, 13 (Esp.), 121 138.

Carvalho-Freitas, MN e Marques, L. (2007). A diversidade através da história: uma inserção no trabalho de pessoas com deficiência. Organizações \& Sociedade, 14 (41), 59-78.

Conselho Nacional de Pessoas com Deficiência e Cuidador na Austrália (2009) Shut Out: A experiência de pessoas com deficiência e suas famílias na Austrália.Relatório Nacional de Consulta da Estratégia para Deficiências. Canberra:Departamento de Famílias, Habitação, Serviços Comunitários e Assuntos Indígenas.

Duggan M (1999) Reflexões sobre minha vida: confissões de um baby boomer. Em: A Cross, J Sherwin, P Collins, B Funnell e M Rodgers (Eds) Reunindo a sabedoria: mudando realidades na vida das pessoas com deficiência (pp. 26-38). Brisbane: Publicações CRU.

Duggan M (2005) Uma humanidade compartilhada. Em: L Shevellar, S Pacey e P Collins (Eds) Sobre ser a mudança que queremos ver ( p36). Brisbane: Publicações CRU.

Emerson E \& Hatton C (2007) Desvantagem socioeconômica, participação e redes sociais e a autoavaliação da saúde de homens e mulheres ingleses com deficiências intelectuais leves e intelectuais moderadas: pesquisa transversal. Revista Europeia de Saúde Pública 18 ( 1) 3137. 


\section{RECIMA21 - REVISTA CIENTÍFICA MULTIDISCIPLINAR}

Flynn R \& Aubry T (1999) Integração de pessoas com deficiências de desenvolvimento ou psiquiátricas: conceitualização e mensuração. Em: R Lemay e R Flynn (1999) (Eds) Um quarto de século de normalização e valorização do papel social: evolução e impacto ( pp271-303) Ottawa: University of Ottawa Press.

Gallagher D (2001) A neutralidade como um ponto de vista moral, confusão conceitual e o debate sobre a inclusão total. Deficiência e Sociedade 16 ( 5) 637-654.

Gannon B e Nolan B (2005) Deficiência e Inclusão Social na Irlanda. Dublin: Autoridade Nacional de Deficiência e Autoridade de Igualdade.

Hoffmann, C., Traverso, L., \& Ruviaro, R. (2013). Contexto de trabalho das pessoas com deficiência no setor público federal. Em Anais do Congresso Nacional IX sobre excelência em gestão (20-22 de Junho) Rio de Janeiro: CNEG.

Instituto Brasileiro de Geografia e Estatística IBGE. (2010). Características gerais da população, religião e pessoas com deficiência.

Jackson R (2008) Segregação e congregação e a conquista de um lar real. CRUcial Times 40. 911.

Kendrick MJ \& Sullivan L (2009) Appraising the leadership challenges of social inclusion. Thelnternational Journal of Leadership in Public Services5 (2) 67-75
GESTÃO INCLUSIVA DA PESSOA COM DEFICIÊNCIA NO AMBIENTE DE TRABALHO Evandro Ferigato

Kendrick MJ (2002) O papel potencial da advocacia em imaginar melhor. Linha de frente 51 26-27.

Kitchin R (1998) 'Out of place', 'knowing one's place': space, power and the exclusion of disabled people. Disability and Society 13 (3) 343-355.

Knudsen B, Florida R \& Rousseau D (2007) Bridging and Bonding: $A$ multi-dimensional approach to regional social capital. Toronto: University of Toronto: the Martin Prosperity Institute. Available from: http://www.creativeclass.com/rfcgdb/articles/Brid ging_and_Bonding.pdf (accessed August 2010).

Lee B (2007) A comunidade: heróis e vilões. Rebentamento de mitos e construção de momento: uma conferência comunitária sobre verdades na vida de pessoas com deficiência. 33-37 Brisbane: Publicações CRU.

Lee B (2008) Pelo menos o arame farpado se foi agora. CRUcial Times 40. 11-12.

Lemay R (2006) Insights de valorização do papel social no enigma da integração social. Retardo mental 44 ( 1) 1 a 12.

Lemay R (2007) Desinstitucionalização de pessoas com deficiência no desenvolvimento: uma revisão da literatura.Jornal Canadense de Saúde Mental Comunitária 28 ( 1) 181-194.

Lengnick-Hall, M.L., Lengnick-Hall, C.A., Andrade, L.S., Drake, B., (2009). "Strategic Human Resource Management: The Evolution of 


\section{RECIMA21 - REVISTA CIENTÍFICA MULTIDISCIPLINAR}

The Field". Human Resource Management Review. 19. 64-85.

Moraes de Souza, AL (2009). Gestão de diversidade e pessoas com deficiência: investigação sobre inserção de pessoa com deficiência em uma Organização Pública Federal (Monografia). Universidade de Brasília, Faculdade de Economia, Administração, Contabilidade e Ciência da Informação e Documentação - FACE, Brasília.

O'Brien CL, Mount B, O'Brien J e Rosen F (2001) Desbravadores: Fazendo o caminho da segregação para a vida comunitária. Siracusa: O Centro de Política Humana, Direito e Estudos sobre Deficiência.

O'Brien J (1999) O gênio do princípio da normalização. Washington, DC: Instituto Nacional de Reabilitação e Pesquisa.

Oliveira, MA, Goulart Júnior, E., \& Fernandes, JM (2009). Pessoas com deficiência no mercado de trabalho: considerações sobre políticas públicas nos Estados Unidos, União Europeia e Brasil. Revista Brasileira de Educação Especial , 15 (2), 219-232.

Putnam, Robert. (1993), "The Prosperous Community: Social Capital and Public Life". The American Prospect, 13: 35-52.

Ribeiro, MA e Carneiro, R. (2009). A inclusão indesejada: as empresas brasileiras enfrentam a Lei de Cotas para pessoas com deficiência no
GESTÃO INCLUSIVA DA PESSOA COM DEFICIÊNCIA NO AMBIENTE DE TRABALHO Evandro Ferigato

mercado de trabalho. Organizações \& Sociedade. 16 (50), 545-564.

Rodrigues, DS, Simonelli, AP, Soares, LB e Camarotto, JA (2009). Caracterização das pessoas com deficiência em idade economicamente ativa e mapeamento das instituições de assistência a agentes no município de São Carlos. Cadernos de Terapia Ocupacional da UFSCar, 17 (2), 107-118.

Sassaki, RK (2003). Vida independente: história, movimento, liderança, conceito, filosofia e fundamentos. São Paulo: RNR.

Schur, L., D. Kruse , J. Blasi e P. Blanck . 2009. "A deficiência é desativada em todos os locais de trabalho? Disparidades no local de trabalho e cultura corporativa." Relações Industriais 48 (3): $381-410$.

Schur, L., Nishii, L., Adya, M., Kruse, D., Bruyère, S. M., \& Blanck, P. (2014). Accommodating employees with and without disabilities. Human Resource Management, 53, 593-621.

Schwartz, A. \& Haber, J. (2006). A ação de Recursos Humanos e a inclusão de pessoas com deficiência (Coleção Febraban de Inclusão Social) . São Paulo: Febraban. Simonelli, AP \& Camarotto, JA (2011). Análise de atividades para a inclusão de pessoas com deficiência no trabalho: uma proposta de modelo. Gestão e Produção, 18 (1), 13-26

Tomlin, M. e E. Haring . 2010 . " Rotas alternativas para o ensino de educadores 


\section{RECIMA21 - REVISTA CIENTÍFICA MULTIDISCIPLINAR}

profissionais ". Jornal de Educação e Formação Profissional 51 (4): 507 - 520 .

Turnbull AP, Turnbull HR e Kyzar K (2009) Cobertura entre famílias e profissionais como catalisadores para uma inclusão ótima: enfoque nos Estados Unidos da América (Parcerias família-profissionais como catalisadores para uma inclusão bem-sucedida: uma perspectiva dos Estados Unidos da América). Revista de Educación 349 69-99.

Violante, RR, \& Leite, LP (2011). A empregabilidade das pessoas com deficiência: uma análise da inclusão social no mercado de trabalho do município de Bauru, SP. Cadernos de Psicologia Social do Trabalho, 14 (1), 73.

Westoby P \& Owen J (2009) A socialidade e geometria da prática de desenvolvimento comunitário. Jornal de Desenvolvimento Comunitário 45 ( 1) 58-74.

\section{GESTÃO INCLUSIVA DA PESSOA COM DEFICIÊNCIA NO AMBIENTE DE TRABALHO Evandro Ferigato}

White GW, Simpson JL, Gonda C, Ravesloot C e Coble Z (2010) Mudando da independência para a interdependência: um modelo conceitual para entender melhor a participação comunitária de centros para consumidores independentes.Journal of Disability Policy Studies 20 ( 4) 233-240.

Wolfensberger W (1998) Uma breve introdução à valorização do papel social: um conceito de alta ordem para abordar a situação das pessoas desvalorizadas socialmente e para estruturar serviços humanos ( $3^{\text {a }}$ edição). Syracuse, NY: Instituto de Treinamento para Planejamento de Serviços Humanos e Liderança e Mudança (Syracuse University).

Wolfensberger W, Thomas S e Caruso G (1996) Algumas das "coisas boas da vida" universais que se espera que a implementação da valorização do papel social torne maisacessível às pessoas desvalorizadas. Revista Internacional de Valorização do Papel Social 2 ( 2) $12-14$ 